\title{
Selective Detection of Formaldehyde Gas Using a Cd-Doped $\mathrm{TiO}_{2}-\mathrm{SnO}_{2}$ Sensor
}

\author{
Wen Zeng ${ }^{1,2}$, Tianmo Liu ${ }^{1, *}$, Zhongchang Wang ${ }^{2, *}$, Susumu Tsukimoto ${ }^{2}$, Mitsuhiro Saito ${ }^{2}$ and \\ Yuichi Ikuhara ${ }^{2}$
}

1 College of Materials Science and Engineering, Chongqing University, Chongqing 400044, P. R. China; E-Mail: zeng_wen1982@yahoo.com.cn

2 World Premier International Research Center, Advanced Institute for Materials Research, Tohoku University, 2-1-1 Katahira, Aoba-ku, Sendai 980-8577, Japan;

E-Mails: tsukimoto@wpi-aimr.tohoku.ac.jp (S.T.); saito@wpi-aimr.tohoku.ac.jp (M.S.); ikuhara@sigma.t.u-tokyo.ac.jp (Y.I.)

* Authors to whom correspondence should be addressed; E-Mails: zcwang@wpi-aimr.tohoku.ac.jp (Z.W.); tmliu@cqu.edu.cn (T.L.); Tel.: +81-22-217-5933; Fax: +81-22-217-5930.

Received: 9 October 2009; in revised form: 28 October 2009 / Accepted: 29 October 2009 / Published: 13 November 2009

\begin{abstract}
We report the microstructure and gas-sensing properties of a nonequilibrium $\mathrm{TiO}_{2}-\mathrm{SnO}_{2}$ solid solution prepared by the sol-gel method. In particular, we focus on the effect of $\mathrm{Cd}$ doping on the sensing behavior of the $\mathrm{TiO}_{2}-\mathrm{SnO}_{2}$ sensor. Of all volatile organic compound gases examined, the sensor with $\mathrm{Cd}$ doping exhibits exclusive selectivity as well as high sensitivity to formaldehyde, a main harmful indoor gas. The key gas-sensing quantities, maximum sensitivity, optimal working temperature, and response and recovery time, are found to meet the basic industrial needs. This makes the Cd-doped $\mathrm{TiO}_{2}-\mathrm{SnO}_{2}$ composite a promising sensor material for detecting the formaldehyde gas.
\end{abstract}

Keywords: volatile organic compound; formaldehyde; $\mathrm{TiO}_{2}-\mathrm{SnO}_{2} ; \mathrm{Cd}$ doping; gas sensor 


\section{Introduction}

The evaluation of indoor air quality is serious environmental issue that is urgently in need of being addressed. Indoor pollutants, which mainly consist of volatile organic compounds (VOCs) such as formaldehyde, benzene, toluene, xylene, and methanol, are well known to enable the so-called building-related sickness [1]. The conventional method used for monitoring indoor VOCs is generally time-consuming and expensive because it involves on-site sampling of indoor air but ensuing analysis of the sampled air in a laboratory [2-5]. To date, there are still no electronic sensors available for in situ detection of indoor VOCs, in particular, the formaldehyde [6], which has already been classified as a probable carcinogen [7-9]. For this reason, extensive research has been conducted on developing a sensor that has a simple device structure and can be put into practical use. To this end, a number of potential sensing materials have been fabricated through a variety of methods [10-12].

Of all the materials investigated, semiconductor metal oxides are promising for monitoring the harmful VOCs owing to their various advantages, for example, simple fabrication process, rapid response and recovery, and low cost. In particular, the oxides $\mathrm{SnO}_{2}$ and $\mathrm{ZnO}$, are of strong current interest because they enable an effective detection of VOC gases, especially formaldehyde [13-15]. However, one of the critical issues currently limiting the wide use of these oxides is their lack of selectivity towards formaldehyde [16]. Therefore, in this work, we propose a new nonequilibrium solid solution, $\mathrm{TiO}_{2}-\mathrm{SnO}_{2}$ composite, in order to improve selectivity as well as sensor response to formaldehyde gas. In particular, we introduce $\mathrm{Cd}$ into the $\mathrm{TiO}_{2}-\mathrm{SnO}_{2}$ composite and investigate how the $\mathrm{Cd}$ doping affects gas-sensing properties. This composite material has been selected deliberately because it is suggested that composite materials may exhibit unusual sensing functionality that is absent in either of their host components [17]. As expected, we find that the Cd-doped $\mathrm{TiO}_{2}-\mathrm{SnO}_{2}$ shows an exclusive selectivity to formaldehyde gas, thereby holding technological promise for fabrication of formaldehyde gas sensors.

\section{Experimental Procedure}

The $\mathrm{TiO}_{2}-\mathrm{SnO}_{2}$ solid powder was prepared using the sol-gel method. First, metal salt precursors were hydrolyzed in a dilute $\mathrm{pH} 3 \sim 5$ solution of ammonium hydroxide. Next, the generated metal salt $\mathrm{SnCl}_{4} \cdot 5 \mathrm{H}_{2} \mathrm{O}$ and tetrabutyl Ti were dissolved in distilled water. The concentration of Ti cation varied from $0.1 \mathrm{~mol} / \mathrm{L}$ to $0.2 \mathrm{~mol} / \mathrm{L}$, but the ratio of $\mathrm{Ti}$ to $\mathrm{Sn}$ was maintained at $1: 5$. To examine the Cd-doping effect, the compound $\mathrm{CdNO}_{2}$ was added to the mixed solution in a drop-by-drop fashion under intense magnetic stirring. The mass ratio of $\mathrm{Cd}$ additive to total metallic ions was estimated to be about $1 \sim 2 \%$. It should be noted that as an initial step, we did not address the potential effect of the mass ratio of $\mathrm{Cd}$ dopant on gas-sensing properties. To basify the mixed solution, ammonium hydroxide was gradually added dropwise until its ultimate $\mathrm{pH}$ reaches 8 , which results in immediate precipitation. After the precipitation, the slurry was first aged for $24 \mathrm{~h}$, filtrated and washed to remove chloride ions, then dried at $353 \mathrm{~K}$ and ground to a uniform powder. The powder was finally annealed at $723 \mathrm{~K}$ for $2 \mathrm{~h}$. For the purpose of comparison, we also prepared pristine $\mathrm{TiO}_{2}-\mathrm{SnO}_{2}$ powder using a similar 
preparation approach. The produced powder was further mixed with diethanolamine and water to form a paste, which was subsequently screen-printed onto an alumina substrate. The substrate is schematically illustrated in Figure 1(a). A set of comb-like Au electrodes were attached at a distance of $200 \mu \mathrm{m}$. The cross-section dimension of the electrodes was fixed at $15 \mathrm{~mm} \times 10 \mathrm{~mm}$ and the potential effect of electrode dimension on sensor response was not addressed in present study. The printed substrate was finally sintered at $773 \mathrm{~K}$ for $3 \mathrm{~h}$, yielding a thick-film gas sensor [Figure 1(b)]. The film thickness after the sintering was estimated to be about 10 20 $\mu \mathrm{m}$.

Figure 1. Schematic of a thick-film gas sensor.
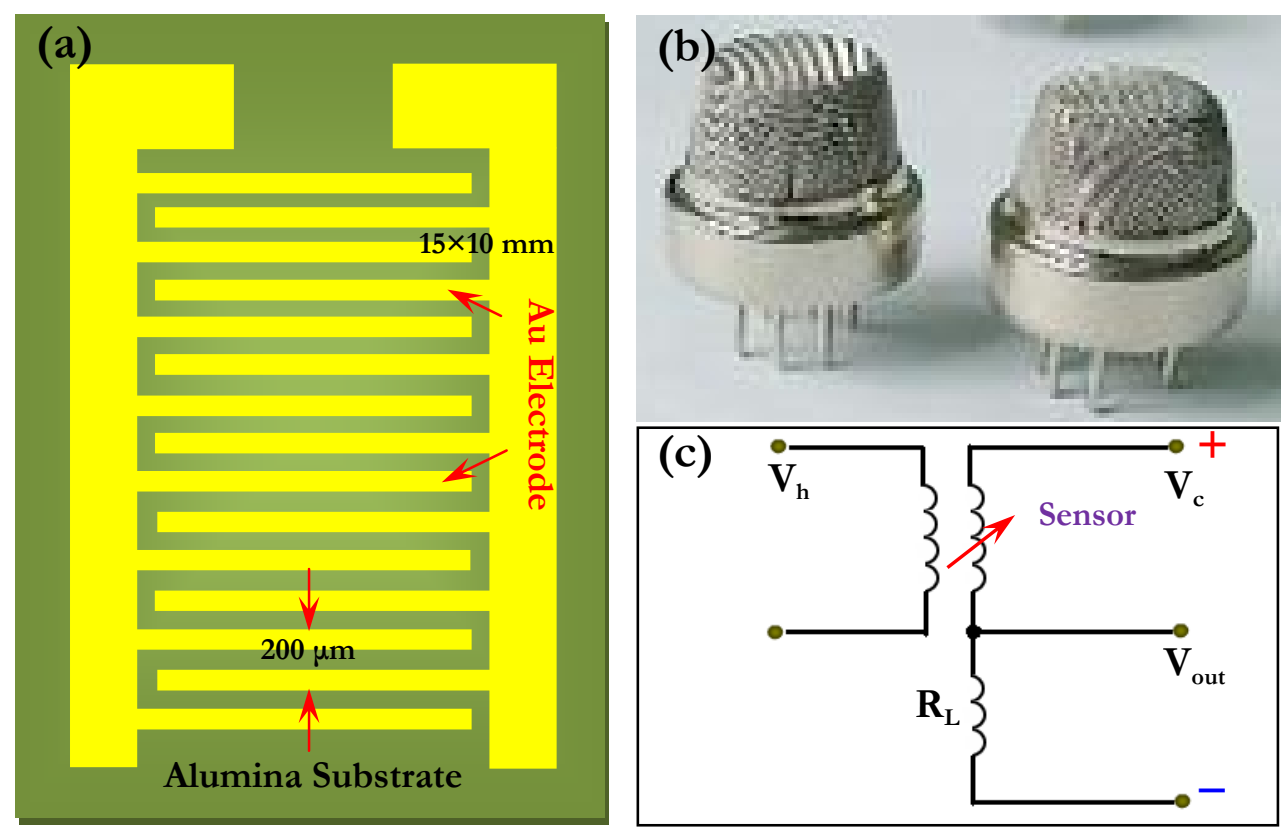

The microstructures of the solid powder and thick film were characterized using X-ray diffraction (XRD) and atomic force microscopy (AFM), respectively. For the XRD, an XD-5A diffractometry with $\mathrm{Cu} \mathrm{K \alpha}$ operated at $30 \mathrm{kV}$ and $100 \mathrm{~mA}$ was used. As for the AFM, we applied a high-speed CSPM4000 microscopy with contact mode, which accurately images surface topography. Gas-sensing properties were measured using a static system controlled by a computer. We used a micro-injector to introduce the VOCs into the chamber and manipulate the VOC concentrations via tuning the input VOC amount alone due to the fixed chamber volume. During the measurement, the sensor was powered at $373 \mathrm{~K}$ for $120 \mathrm{~h}$ in air and operated at $303 \mathrm{~K}$ under a relative humidity of $40 \%$. The gas sensitivity was defined as a ratio of resistance $\left(R_{0}\right)$ in air to that in test gas $(R)$. As for the measurement of voltage, we adopted a circuit shown in Figure 1(c), which could be divided into a heating and measuring part. Clearly, the output voltage varied with the type and concentration of test gas. 


\section{Results and Discussion}

\subsection{Composition and Microstructure of Gas Sensing Materials}

To determine chemical composition of the prepared powder, we performed XRD analysis, as shown in Figure 2, where textural orientations of the detected matters are given as well for easy reference. From Figure 2(a), one can clearly see $\mathrm{TiO}_{2}$ and $\mathrm{SnO}_{2}$ peaks in the undoped case, as expected from the aforementioned preparation process. However, no $\mathrm{Cd}$ related diffraction peak is detected in the doped case [Figure 2(b)], which is mainly attributed to the small amount of $\mathrm{Cd}$ we doped. In light of the approximate relationship between mean particle size $(D)$ and full width at high maximum of XRD peak $\beta$ (i.e., Scherrer equation) [18]: $D=0.89 \lambda /(\beta \cos \theta)$, where $\lambda$ is the $\mathrm{X}$-ray wavelength (1.541 $\AA$ for $\mathrm{Cu}$ ) and $\theta$ is the Bragg angle, the mean particle sizes for the undoped and doped samples were estimated to be about $32 \mathrm{~nm}$ and $30 \mathrm{~nm}$, respectively. This means that the Cd doping has a negligible effect on the particle size of the $\mathrm{TiO}_{2}-\mathrm{SnO}_{2}$ composite.

Figure 2. XRD spectra for (a) undoped and (b) Cd-doped $\mathrm{TiO}_{2}-\mathrm{SnO}_{2}$ powder. Note that the T represents $\mathrm{TiO}_{2}$ and the $\mathrm{S}$ represents $\mathrm{SnO}_{2}$.

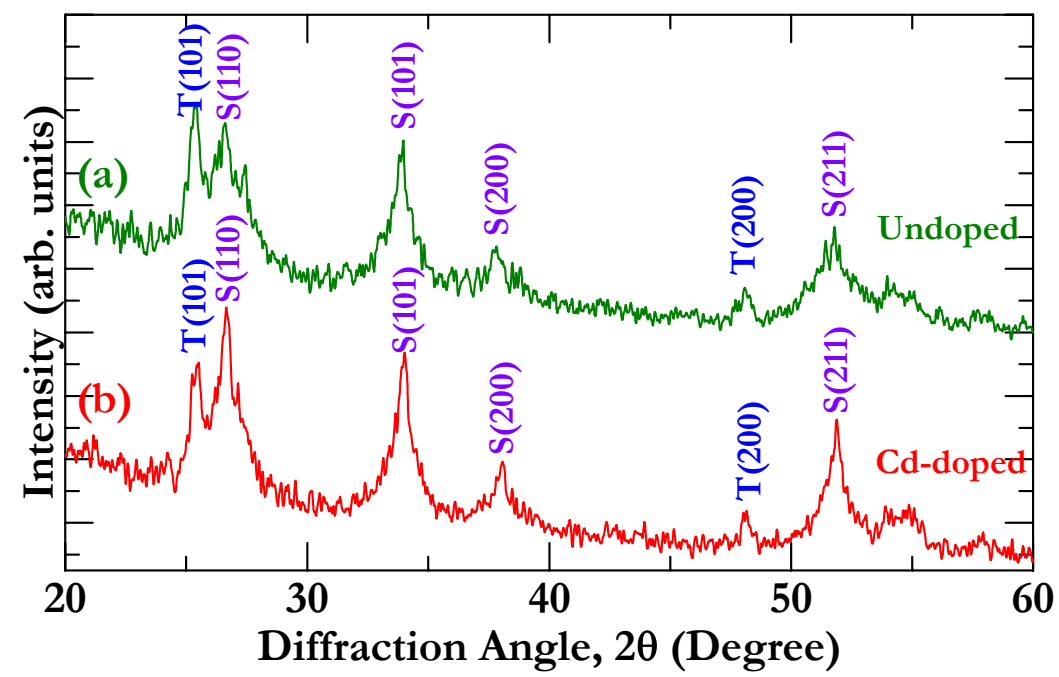

To analyze the elemental species of the thick film, we further show in Figure 3 the energy-dispersive X-ray spectroscopy (EDS) spectrum. We notice that the film is mainly composed of $\mathrm{Ti}, \mathrm{Sn}$, and $\mathrm{O}$, in accordance with chemical composition of the prepared powder. The mass ratio of $\mathrm{Ti}$ to $\mathrm{Sn}$ is estimated to be about 1:5 (Figure 3), demonstrating that we have successfully synthesized the desired composite. Figure 4 shows an AFM image of the surface morphology for both the pristine and doped thick film. Many uniform islands can be observed on the surface, which shows that both films have good crystal shape and even grain size. In comparing the surface morphology of pristine $\mathrm{TiO}_{2}-\mathrm{SnO}_{2}$ film with that of doped one, we see that they are similar, which means that the Cd doping affects surface morphology only slightly. 
Figure 3. EDS spectrum of the $\mathrm{TiO}_{2}-\mathrm{SnO}_{2}$ thick film.

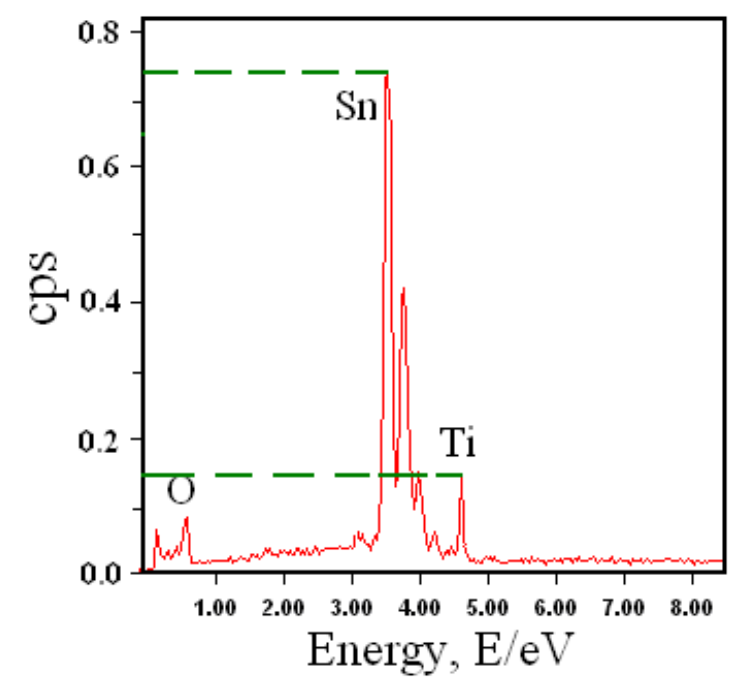

Figure 4. AFM images for (a) pristine and (b) Cd-doped thick films.
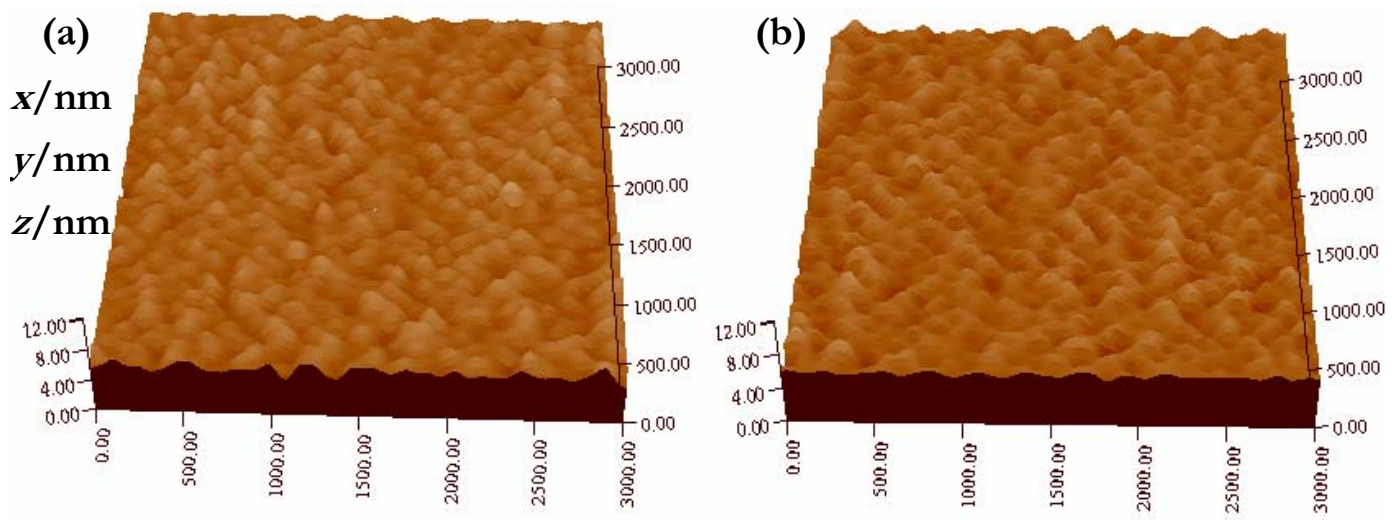

\subsection{Gas Sensing Properties}

To investigate further how the doping influences sensing properties, we tested the responses of the pristine and doped sensors to different types of VOC gases such as formaldehyde, benzene, toluene, xylene, and methanol. Figure 5(a) shows gas sensitivities under various temperatures, where one can see that the doped sensor exhibits exclusive selectivity to formaldehyde. It should be noted that an understanding of the underlying origin of this exclusive selectivity has not been developed yet, which will be an important future task. The highest sensitivity to the formaldehyde is estimated to be 32 , much higher than that to other examined gases (less than 10). Evidently, this demonstrates that the Cd-doped sensor shows good selectivity to formaldehyde, which is therefore promising for practical device applications. From this figure, we further determine the optimum operating temperature to be about $593 \mathrm{~K}$ because maximum sensor response to the formaldehyde is observed at this temperature. This can be understood by considering that a dynamic equilibrium state will occur between the initial adsorption and the subsequent desorption, as the operating temperature keeps increasing. The 
equilibrium state therefore gives rise to a maximum sensitivity, as seen in Figure 5. Compared to the doped case [Figure 5(a)], the sensitivity of pristine sensor is much lower with a maximum value of less than 5 [Figure 5(b)], although the pristine sensor retains the highest sensor response to formaldehyde. We thus conclude that the $\mathrm{Cd}$ is an effective dopant in improving response and selectivity of $\mathrm{TiO}_{2}-\mathrm{SnO}_{2}$ composite to formaldehyde.

Figure 5. Sensitivity of the sensor fabricated using (a) Cd-doped and (b) pristine $\mathrm{TiO}_{2}-\mathrm{SnO}_{2}$ powder under a gas concentration of $200 \mathrm{ppm}$. Note that the sensitivity scale for the doped case is much larger than that for the undoped case.

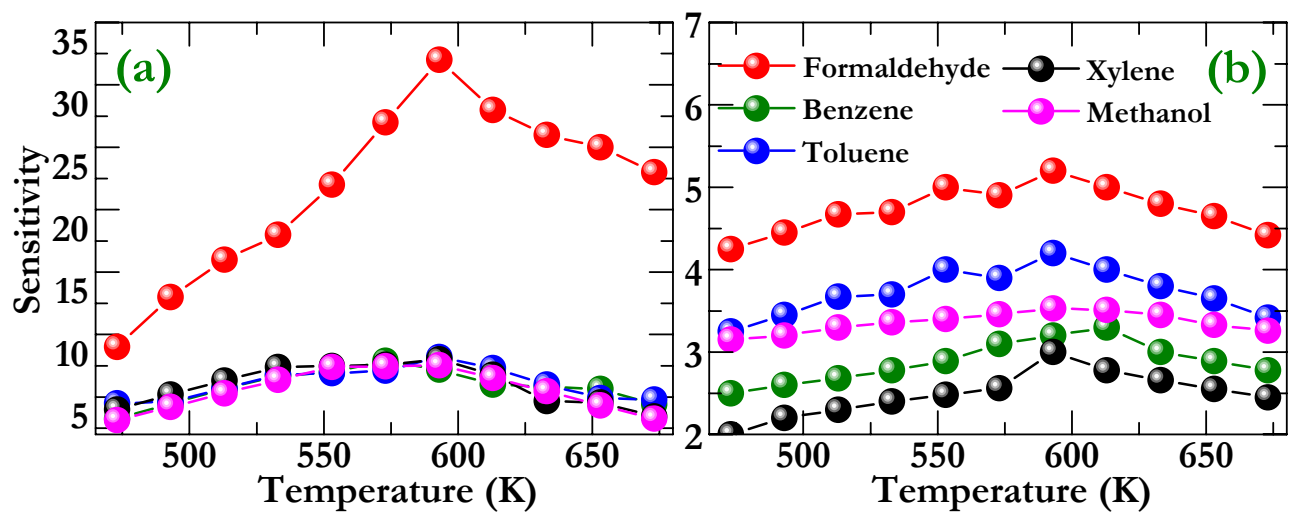

Apart from testing the selectivity, we have examined sensitivity of doped sensor as a function of gas concentration. Figure 6 shows sensitivity to the formaldehyde under various concentrations at $593 \mathrm{~K}$. Clearly, the sensitivity increases sharply as the gas concentration ranges from $50 \mathrm{ppm}$ to $450 \mathrm{ppm}$ but saturates when the concentration increases further. It is worth noting that a sensitivity corresponding to concentration of $100 \mathrm{ppm}$ has already reached a value of more than 15 , a criterion required for practical application.

Figure 6. Variation of sensitivity as a function of formaldehyde gas concentration for the Cd-doped sensor. The operating temperature is maintained at $593 \mathrm{~K}$.

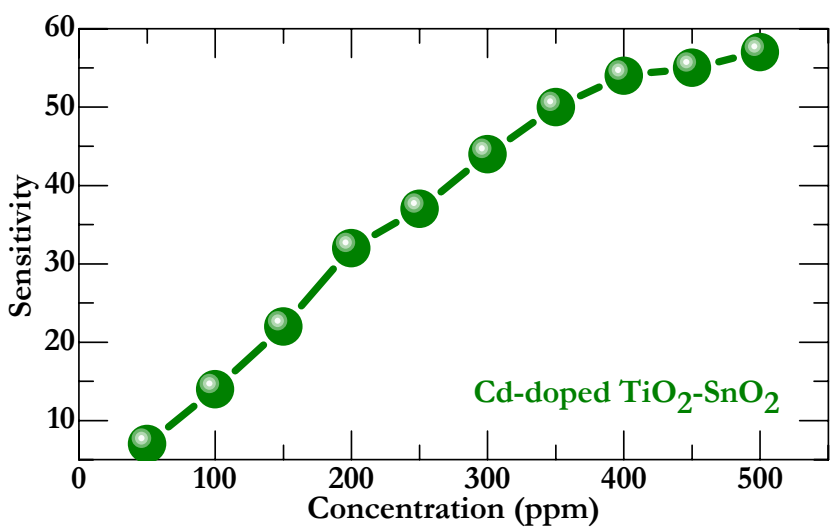

Figure 7 presents a representative response-recovery characteristic for the sensor operated at $593 \mathrm{~K}$ under a formaldehyde gas concentration of $200 \mathrm{ppm}$. The response and recovery times are two key quantities for a sensor, which are defined as the time needed to reach $90 \%$ response (recovery) when 
gas is in (out). As seen in this figure, voltage for both the undoped and doped sensor increases sharply when gas is in but returns to its original state while gas is out. The major difference between the two cases is that the voltage for the doped sensor is substantially larger than that for the pristine one at working stage, verifying again significant effect of $\mathrm{Cd}$ doping on sensor response improvement. In light of the definition describe above, the response and recovery times for the doped sensor are evaluated to be about $25 \mathrm{~s}$ and $17 \mathrm{~s}$, respectively, which meet the basic demands for an industrial application. These short times, together with the high sensor response and exclusive selectivity, suggest that the $\mathrm{Cd}$-doped $\mathrm{TiO}_{2}-\mathrm{SnO}_{2}$ may hold the potential for developing a formaldehyde gas sensor.

Figure 7. Response-recovery property for sensors fabricated using undoped and Cd-doped composite materials.

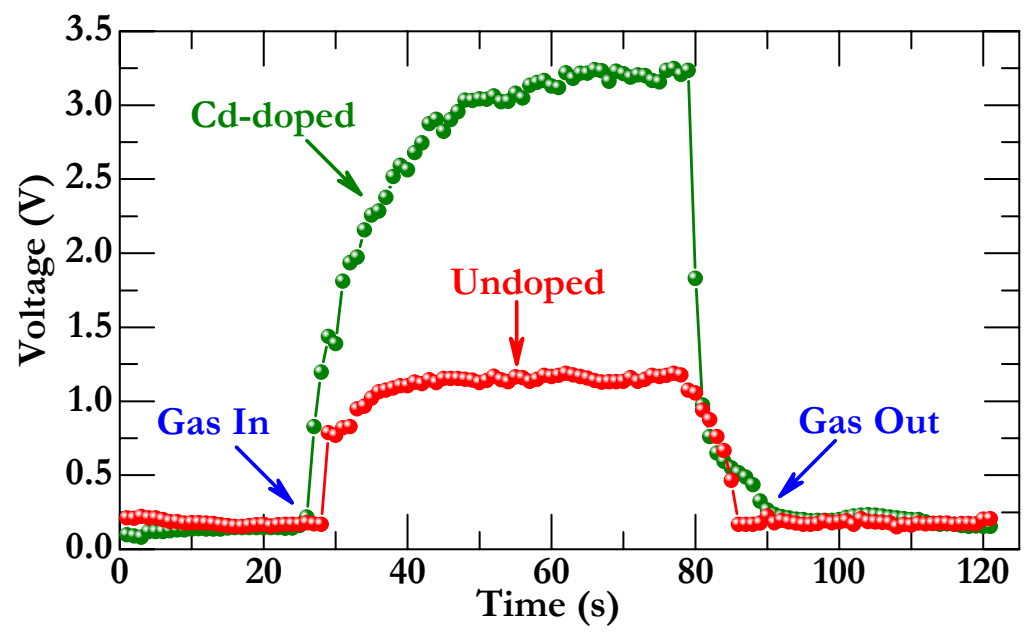

\subsection{Gas Sensing Mechanism}

Although many works have been conducted on $\mathrm{TiO}_{2}$ or $\mathrm{SnO}_{2}$-based sensor, its gas-sensing mechanism remains controversial. The current understanding of the sensing behaviors of $\mathrm{TiO}_{2}\left(\mathrm{SnO}_{2}\right)$ material, which is based mainly on experimental studies via a trial-and-error design fashion, can be summarized in three main points: (1) gas sensing process is dominantly controlled by the surface of materials and how the surface chemically absorbs oxygen, (2) once target gases, for example VOC gases, are introduced, oxidization reaction takes place on sensor surface in the following way:

$$
\mathrm{VOC}+\mathrm{O}^{-} \rightarrow \mathrm{VOC}-\mathrm{O}+\mathrm{e}^{-} ; \mathrm{VOC}+\mathrm{O}^{2-} \rightarrow \mathrm{VOC}-\mathrm{O}+2 \mathrm{e}^{-}
$$

(3) gas sensor response may depend critically on the amount of pre-absorbed oxygen. The results presented in this paper demonstrate that the Cd-doped $\mathrm{TiO}_{2}-\mathrm{SnO}_{2}$ material has a significantly higher sensor response to formaldehyde than the pristine material. This enhancement of sensor response can be presumably attributed to the $\mathrm{Cd}$ additive, which may provide additional sites for adsorbing oxygen. Consequently, as reductive gas is introduced (Figure 8), more oxidization occurs probably on the $\mathrm{Cd}$ surface, which generates more electrons onto the $\mathrm{TiO}_{2}-\mathrm{SnO}_{2}$ surface. These electrons would enhance 
surface conductivity noticeably, which can therefore reduce surface resistance considerably [19-22], as observed in the response and recovery curves (Figure 7).

Figure 8. Schematic plot illustrating the sensing mechanism of the Cd-doped sensor. Note that the $\mathrm{Cd}$ and $\mathrm{O}$ represent the interaction between $\mathrm{Cd}$ additives and pre-absorbed oxygen atoms.

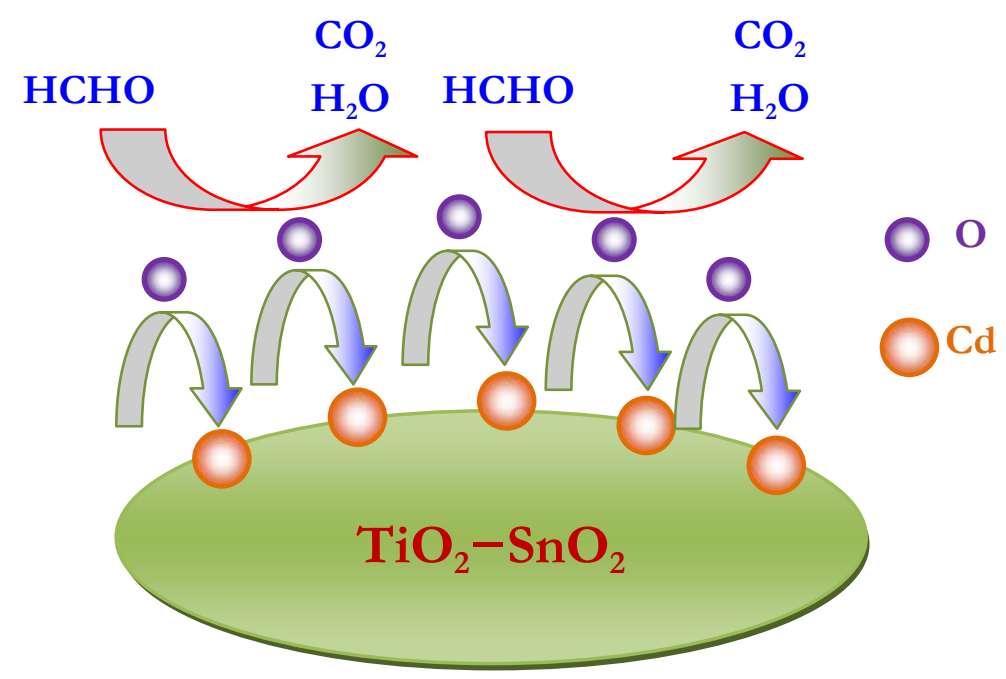

\section{Conclusions}

We have applied a sol-gel method to fabricate nonequilibrium $\mathrm{TiO}_{2}-\mathrm{SnO}_{2}$ solid solutions and investigated their microstructures and gas-sensing properties. In particular, we have focused on the effect of $\mathrm{Cd}$ doping on gas-sensing properties. We have found that doping is essential for improving both the sensitivity and selectivity of the $\mathrm{TiO}_{2}-\mathrm{SnO}_{2}$-based sensor towards formaldehyde gas. The maximum sensitivity for the doped sensor is found to be 32 under a formaldehyde gas concentration of $200 \mathrm{ppm}$ and the optimum operating temperature to be $593 \mathrm{~K}$. Moreover, the response and recovery times are estimated to be $25 \mathrm{~s}$ and $17 \mathrm{~s}$, respectively. These findings demonstrate the potential use of the $\mathrm{Cd}$-doped $\mathrm{TiO}_{2}-\mathrm{SnO}_{2}$ as a formaldehyde gas-sensing material, and this paper presents a possibility for increasing the selection of materials available for other types of gas sensors.

\section{Acknowledgements}

This work was supported in part by a Grant-in-Aid for Scientific Research on Priority Area, “Atomic Scale Modification (474)", from MEXT of Japan, and a National 973 Major Project of China, "The Key Fundamental Problem of Processing and Preparation for High Performance Magnesium Alloy" under Grant No. 2007CB613700. One of the authors (W. Z) thanks the Chinese Scholarship Council (CSC) project for financial support (LJC20093012). 


\section{References and Notes}

1. Kim, W.J.; Terada, N.; Nomura, T.; Takahashi, R.; Lee, S.D.; Park, J.H.; Konno, A. Effect of formaldehyde on the expression of adhesion molecule in nasal microvascular endothelial cell: the role of formaldehyde in the pathogenesis of sick building syndrome. Clin. Exp. Allergy 2002, 32, 287-295.

2. Gardner, J.W.; Gardner, W.E. The role of the electronic nose in conditioning. Insight 1997, 39, $865-869$.

3. Odlyha, M.; Foster, G.M.; Cohen, N.S.; Sitwell, C.; Bullock, L. Microclimate monitoring of indoor environments using piezoelectric quartz crystal humidity sensors. J. Environ. Monit. 2000, $2,127-131$.

4. Arnold, C.; Harms, M.; Goschnick, J. Air quality monitoring and fire detection with the Karlsruhe electronic micronose KAMINA. IEEE Sens. J. 2002, 2, 179-188.

5. Zampolli, S.; Elmi, I.; Ahmed, F.; Passini, M.; Cardinali, G.C.; Nicoletti. S.; Dori, L. An electronic nose based solid state sensor arrays for low-cost indoor air quality monitoring applications. Sens. Actuat. B: Chem. 2004, 101, 39-46.

6. Xu, J.; Jia, X.; Lou, X.; Xi, G.; Han, J.; Gao, Q. Selective detection of HCHO gas using mixed oxides of $\mathrm{ZnO} / \mathrm{ZnSnO}_{3}$. Sens. Actuat. B: Chem. 2007, 120, 694-699.

7. Wood, R.W.; Coleman, J.B. Behavioral evaluation of irritant propertoes of formaldehyde. Toxicol. Appl. Pharmacol. 1995, 130, 67-72.

8. Suzuki, Y.; Nakano, N.; Suzuki, K. Portable sick house syndrome gas monitoring system based on novel colormetric reagents for the highly selective and sensitive detection of formaldehyde. Environ. Sci. Technol. 2003, 37, 5696-5700.

9. Nakano, N.; Nagashima, K. An automatic monitor of formaldehyde in air by a monitoring tape method. J. Environ. Monit. 1999, 1, 255-258.

10. Chu, X.F.; Chen, T.Y.; Zhang, W.B.; Zheng, B.Q; Shui, H.F. Investigation on formaldehyde gas sensor with $\mathrm{ZnO}$ thick film prepared through microwave heating method. Sens. Actuat. B: Chem. 2009, 142, 49-54.

11. Teleki, A.; Pratsinis, S.E.; Kalyanasundaram. K.; Gouma, P.I. Sensing of organic vapors by flame-made $\mathrm{TiO}_{2}$ nanoparticles. Sens. Actuat. B: Chem. 2006, 119, 683-690.

12. Tang, L.; Li, Y.M.; Xu, K.L.; Hou, X.D.; Lv, Y. Sensitive and selective acetone sensor based on its cataluminescence from nano- $\mathrm{La}_{2} \mathrm{O}_{3}$ surface. Sens. Actuat. B: Chem. 2008, 132, 243-249.

13. Lee, D.S.; Jung, J.K.; Lim, J.W.; Huh, J.S.; Lee, D.D. Recognition of volatile organic compounds using $\mathrm{SnO}_{2}$ sensor array and pattern recognition analysis. Sens. Actuat. B: Chem. 2001, 77, $228-236$.

14. Zhu, B.L.; Xie, C.S.; Wang, W.Y. Improvement in gas sensitivity of ZnO thick film to volatile organic compounds (VOCs) by adding $\mathrm{TiO}_{2}$. Mater. Lett. 2004, 58, 624-629.

15. Srivastava, A.K. Detection of volatile organic compounds (VOCs) using $\mathrm{SnO}_{2}$ gas-sensor array and artificial neural network. Sens. Actuat. B: Chem. 2003, 96, 24-37. 
16. Achmann, S.; Hämmerle, M.; Moos, R. Amperometric enzyme-based gas sensor for formaldehyde: impact of possible interferences. Sensors 2008, 8, 1351-1365.

17. Gopal Reddy, C.V.; Cao, W.; Tan, O.K.; Zhu, W.; Akbar, S.A. Selective detection of ethanol vapor using $\mathrm{xTiO}_{2}-(1-\mathrm{x}) \mathrm{WO}_{3}$ based sensor. Sens. Actuat. B: Chem. 2003, 94, 99-102.

18. Bhagwat, M.; Shah, P.; Ramaswamy, V. Synthesis of nanocrystalline $\mathrm{SnO}_{2}$ powder by amorphous citrate route. Mater. Lett. 2003, 57, 1604-1611.

19. Yamazoe, N.; Sakai, G.; Shimanoe, K. Oxide semiconductor gas sensors. Catal. Surv. Asia 2003, 7, 63-75.

20. Williams, D.E. Semiconducting oxides as gas-sensitive resistors. Sens. Actuat. B: Chem. 1999, 57, $1-16$.

21. Neri, G.; Bonavita, A.; Milone, C.; Galvagno, S. Role of the Au oxidation state in the CO sensing mechanism of Au/iron oxider-based gas sensors. Sens. Actuat. B: Chem. 2003, 93, 402-408.

22. Wu, X.H.; Wang, Y.D.; Li, Y.F.; Zhou, Z.L. Electrical and gas sensing properties of perovskite-type $\mathrm{CdSnO}_{3}$ semiconductor material. Mater. Chem. Phys. 2002, 77, 588-593.

(C) 2009 by the authors; licensee Molecular Diversity Preservation International, Basel, Switzerland. This article is an open-access article distributed under the terms and conditions of the Creative Commons Attribution license (http://creativecommons.org/licenses/by/3.0/). 